\title{
RAIL PASSENGER EQUIPMENT COLLISION TESTS: ANALYSIS OF STRUCTURAL MEASUREMENTS
}

\author{
Kristine J. Severson \\ David C. Tyrell \\ Volpe National Transportation Systems Center \\ U.S. Department of Transportation \\ Cambridge, MA 02142
}

\author{
A. Benjamin Perlman \\ Tufts University \\ Medford, MA 02155
}

\begin{abstract}
A two-car full-scale collision test was conducted on April 4,2000 . Two coupled rail passenger cars impacted a rigid wall at $26 \mathrm{mph}$. The cars were instrumented with strain gauges, accelerometers, and string potentiometers, to measure the deformation of critical structural elements, the longitudinal, vertical, and lateral car body accelerations, and the displacements of the truck suspensions. Instrumented crash test dummies were also tested in several seat configurations, with and without lap and shoulder belts.
\end{abstract}

The objectives of the two-car test were to measure the gross motions of the car, to measure the force/crush characteristic, to observe the car-to-car interaction, to observe failure modes of the major structural components, and to evaluate selected occupant protection strategies. The measurements taken during the test were used to refine and validate existing computer models of conventional passenger rail vehicles. This test was the second in a series of collision tests designed to characterize the collision behavior of rail vehicles.

The two-car test resulted in approximately 6 feet of deformation at the impacting end of the lead vehicle, and a few inches of deformation at the coupler. The cars remained coupled, but buckled in a saw-tooth mode, with a 15-inch lateral displacement between the cars after the test.

The test data from the two-car test compared favorably with data from the single-car test, and with analysis results developed with a lumped-mass computer model. The model is described in detail. The methods of filtering and interpreting the test data are also included.

\section{INTRODUCTION}

As part of the Federal Railroad Administration's Equipment Safety Research Program, a series of full-scale impact tests are being conducted on rail passenger vehicles (see Table 1.) The first two tests have already been conducted. The third test is planned for November 2000.

Table 1. Planned Full-Scale Impact Tests

\begin{tabular}{|c|c|}
\hline Test Conditions & Equipment Type \\
\hline Single-car impact with rigid wall & \multirow{2}{*}{$\begin{array}{c}\text { Conventional } \\
\text { Equipment }\end{array}$} \\
\cline { 1 - 1 } Two-car impact with rigid wall & \\
\cline { 1 - 1 } $\begin{array}{c}\text { Cab car-led train impact with } \\
\text { locomotive-led train }\end{array}$ & Modified \\
\cline { 1 - 1 } Single-car impact with rigid wall & Equipment \\
\cline { 1 - 1 } Two-car impact with rigid wall & \\
\cline { 1 - 1 } $\begin{array}{c}\text { Cab car-led train impact with } \\
\text { locomotive-led train }\end{array}$ & \\
\hline
\end{tabular}

The primary objective of these tests is to improve the protection provided for passengers and operators in the event of a collision. In order to reach this ultimate objective, there are several intermediate objectives.

The first series of tests involves existing equipment built to North American equipment standards. These tests will establish a baseline of crashworthiness for conventional equipment. The second series of tests will be conducted on equipment that has been modified to improve crashworthiness by absorbing collision energy at the vehicle ends while preserving the occupied areas. This set of tests is intended to verify the effectiveness of the structural modifications. The results from the conventional and modified equipment tests will then be compared to evaluate the improvement in protection provided to passengers and operators. 
A secondary objective of the tests is to validate the computer models that have been developed as part of the rail vehicle crashworthiness research. Validated finite element models of conventional equipment can be used to assist in the design of modified equipment. Validated collision dynamics models can be used to analyze the behavior of a train in potential collision scenarios.

For each test, there are also test-specific objectives. The objectives of the two-car test were to:

- measure the gross motion of the car body

- measure the force/crush behavior

- observe the car-to-car interaction

- observe the failure modes of major structural members

- evaluate the effectiveness of several occupant protection strategies

The first full-scale crash test consisted of a single passenger car colliding with a rigid impact wall at $35 \mathrm{mph}$ $[1,2]$. This test focused on the behavior of a single car without the added complication of a second car.

This paper compares the data from the two-car test with the results of a collision dynamics model. Companion papers cover details on the test requirements and implementation [3] and the interior seat/occupant analysis [4].

\section{BACKGROUND}

There are three technical issues that require full-scale crash test data to further the understanding of train collisions:

- $\quad$ Large crush distances

- Car-to-car interactions

- Secondary impact environment

In a train collision, large lengths of the cars can crush. Significant parts of the car body structure can also be separated from the car. The modeling of material failure and structural crush much greater than 3 feet have not been as well validated as other aspects of the dynamic collapse of structures. The collision speeds for these tests have been chosen to develop enough crush at the impacting end of the cars in order to validate finite element (FE) and collision dynamics (CD) models with large crush distances.

During train collisions, one car can override another car, or the trainset can buckle laterally. Override occurs when the relatively strong underframe of one car rides up and over the underframe of an adjacent car, causing extensive crush of the relatively weak superstructure of the adjacent car. Lateral buckling occurs when the cars in the train end up in a zig-zag pattern. Lateral buckling can lead to encroachment of adjacent track, side-to-side impacts between cars, and impacts with wayside structures. Both override and lateral buckling are consequences of the gross motions of the cars (e.g. the bouncing and pitching of the car on its suspension), the initial geometry of the coupling system and the cars, and the dynamic collapse of the car structures during the collision. The impact test of two coupled cars was designed to improve the understanding of the coupled car-to-car interaction, and the conditions that lead to car buckling.

The secondary impact refers to the collision between an occupant and some part of the car interior - likely the seat ahead of the occupant. To study this collision between the occupant and the seat, dynamic sled tests have been performed with crash test dummies in rail passenger seats. In these seat tests, assumptions were made in an attempt to simulate actual conditions. For instance, the crash pulse, or vehicle acceleration time history, was calculated from a single degreeof-freedom lumped mass model. Also, only the longitudinal motion of the train has been considered - the influence of the pitch and yaw motions of the car on occupant response has been neglected. The full-scale tests will demonstrate whether or not these simplifications and assumptions are reasonable.

Several intermediate steps were taken prior to the full-scale testing described in this paper. Static and dynamic tests have been conducted on full-scale end beam/draft sill assemblies to measure the failure load of the end beam when loaded longitudinally at the base of the corner post [5]. Sub-scale static and dynamic tests have been conducted on assemblies representing the side sill and body sheet metal of half a car [6]. These tests were performed to evaluate the influence of the body shell and support stringers on the longitudinal strength of the car body as a whole. Several dynamic sled tests have also been performed using different passenger seat designs and instrumented crash test dummies $[7,8]$. The seat tests were designed to evaluate the structural integrity of the seat, and to measure the forces and accelerations imparted to the occupant under collision conditions.

\section{TWO-CAR TEST DESCRIPTION}

Two coupled commuter rail cars impacted a rigid barrier at $26.25 \mathrm{mph}$. The impact speed was chosen in order to crush the impacting end of the lead car by approximately 5 feet, as in the single-car test. The kinetic energy in the two-car test was roughly the same as in the single-car test ( 3 million ft-lbs.).

Both cars were Pioneer cars, designed and built by the Budd Company [9]. A locomotive was used to push the coupled cars down a constant-gradient slope and release them such that they impacted the wall at the desired speed.

The cars were stripped of the original passenger seats and some auxiliary equipment to make room for the interior seat/occupant experiments. About 10,000 lbs. of ballast were added to the cars, resulting in a total weight of approximately 75,000 lbs. for each car. The weight of a fully equipped car used in passenger service is about $100,000 \mathrm{lbs}$. Conducting the 
test with the lighter vehicle results in less damage than would occur in a test with a fully equipped vehicle at the same speed.

The cars were instrumented to measure material strain, three-dimensional acceleration of the car body, vertical displacements of the truck suspension, and longitudinal forces and displacements at the coupler. 107 channels of data were collected from the structural car body instrumentation. The cars were also equipped with crash test dummies in several different seating configurations.

The test was filmed using five high-speed cameras and three video cameras, positioned to focus on the impacting end of the lead car, and the coupled connection between cars. A photometric analysis of the film was performed to calculate the displacement of several target points on the cars during the impact. This photometric data was used in processing the accelerometer data.

\section{MODELING APPROACH}

The flow chart in Figure 1 illustrates the approach used to model the full-scale collision tests. FE models provide initial estimates for the force/crush behavior of discrete nonlinear springs in the collision dynamics analysis. A CD model can then be used to estimate the forces and displacements in fullscale testing as well as the acceleration environment for interior occupant analysis. Test measurements are used to modify CD parameters to increase the fidelity of estimated behavior. The validated $C D$ model can then be employed to estimate crashworthiness behavior under collision conditions for which test data is not available.

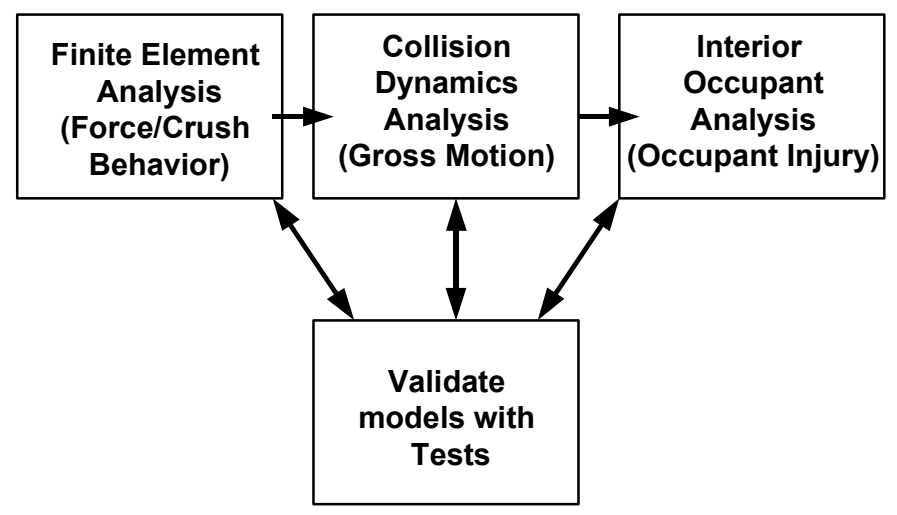

Figure 1. Modeling Approach

Prior to the full-scale impact tests, the force-crush behavior of the vehicle end structure was estimated by exercising a detailed FE model of a single passenger rail vehicle (Figure 2) [10]. The model represents an Amfleet car, built by Budd Co. The geometry and materials of the primary structural members, i.e. draft sill, center sill, side sills, cant rails, collision and corner posts, are very similar in both the Amfleet and Pioneer cars. The FE model did not account for the suspension characteristics or the vehicle/track interaction.

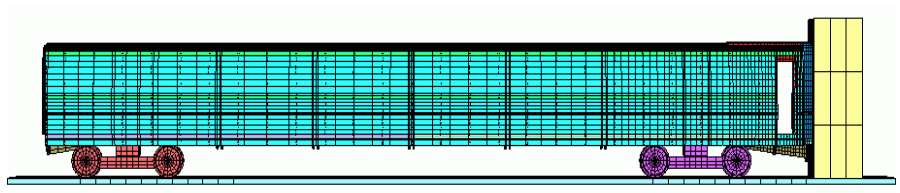

Figure 2. Finite Element Model

A lumped-mass CD model (Figure 3a) was used to estimate the gross motion of the car and the collapse of the end structure. The CD model uses a series of discrete masses connected by non-linear springs and dampers. It runs much more quickly than the FE model and the force/crush behavior is more readily modified to better estimate the gross motion of the car during the impact test.

Following the single-car test, the CD model was modified to better represent the test results. To estimate the results of the two-car test, a trailing car was added to the model (Figure 3b). The trailing car and coupled connection between the cars was adapted from a CD model previously developed to investigate lateral buckling [11]. Following the two-car test, the model of the impacting car was modified to better reflect the results of both tests. The impacting car is identical in the single-car and two-car models. This paper compares the two-car test data with the results of the corresponding CD model.

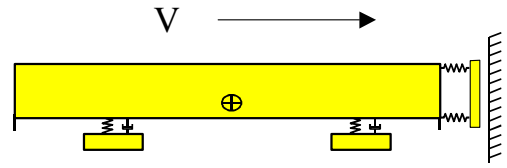

(a)

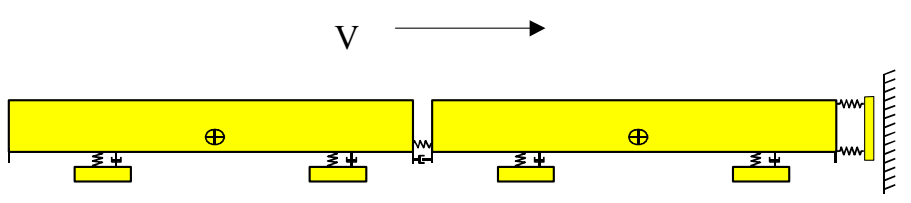

(b)

Figure 3. Schematic of Collision Dynamics Model

The impacting car in both CD models consists of four rigid masses that represent the front portion of the vehicle, the trucks and the main car body. The trailing car in the two-car model does not have a separate mass representing the leading end of the vehicle, because little crush was expected between the two cars. The model is capable of 3-D motion since each mass is allowed three translational and three rotational degrees of freedom. However, for this study the masses representing the front end and the main car body were constrained to translate 
longitudinally with respect to one another. Non-linear springs and dampers that represent the crushable end structure, the truck/car body suspension, and the coupler, were used to connect the masses. For more detail on the parameters used in the model, see Appendix A.

The car body accelerations calculated with the CD model are used as input to an interior seat/occupant model (Figure 4). This model also uses the force-deflection behavior of passenger seats that has been previously calculated during static tests $[7,8]$. Using the interior dynamics model, the forces and accelerations experienced by occupants in a collision can be estimated. Using these forces and accelerations, injury criteria for the head, neck, chest and femur can be calculated. The injury criteria can be used to evaluate and compare the level of protection provided to occupants under different collision conditions.

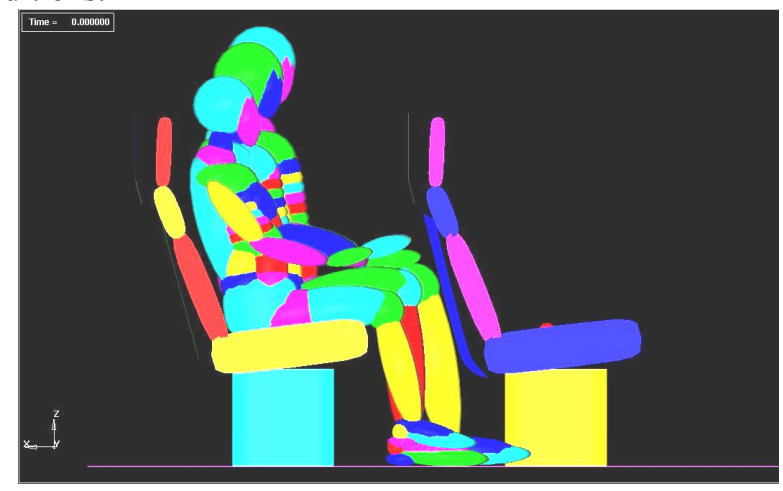

Figure 4. Interior Seat/Occupant Model

\section{PROCESSING OF TEST DATA}

The total force on the wall as a function of time was estimated by multiplying the mass of each car with the acceleration of each car. The sum of the two products is the estimated force time history at the wall:

$$
F_{t}(t)=M_{1} * A_{1}(t)+M_{2} * A_{2}(t)
$$

The displacement time history of the leading vehicle was calculated by integrating the acceleration time history of the leading vehicle twice. The force was plotted against the doubleintegrated displacement time history to represent the force on the wall as a function of crush of the impacting vehicle.

The raw accelerometer data contained components attributable to car body flexibility. The data was filtered in order to remove the high-frequency content while retaining the essential rigid body motion of the car body. The filtered accelerometer data was then integrated to calculate the corresponding velocity and displacement data.

The choice of cut-off frequency has a significant effect on the integrated displacement data. Comparison of the integrated displacement data and the photometric displacement data was used to define the appropriate cut-off value. The accelerometer nearest the CG was chosen to represent the gross longitudinal motion of the vehicle. Displacement time histories integrated from this accelerometer and filtered at several frequencies are plotted in Figure 5, along with the photometric displacement data for comparison.

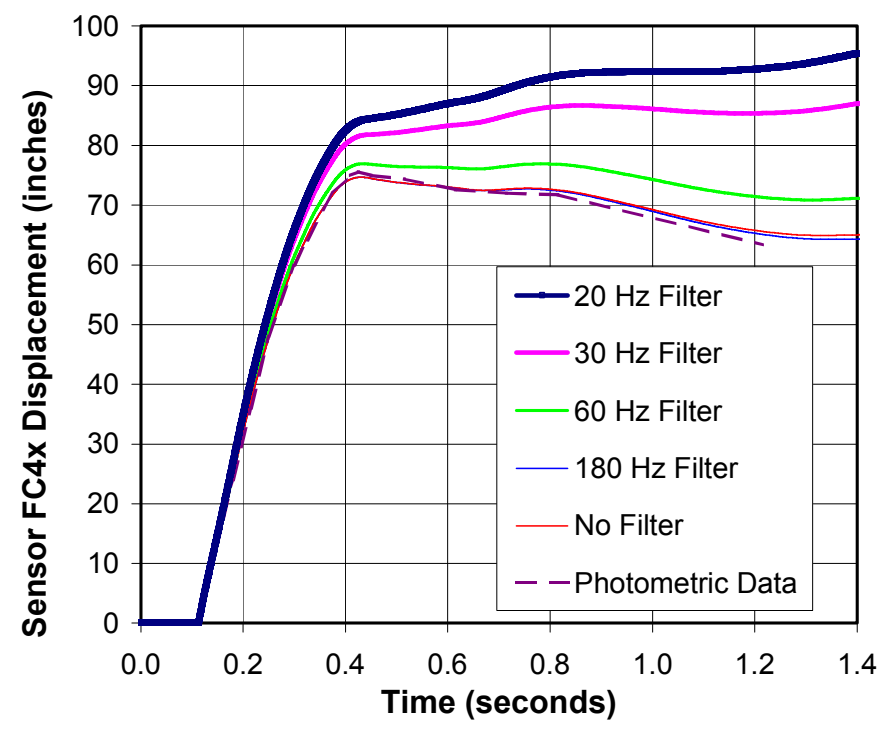

Figure 5. Comparison of Effect of Filtering Frequency on Displacement Time History

To minimize the error in integrated displacement, the accelerometer signal was processed in accordance with SAE J211.1 (Surface Vehicle Recommended Practice Instrumentation for Impact Tests). To compute the acceleration, a CFC 60 Butterworth 4-pole phaseless digital filter was used. To compute the displacement, a CFC 180 Butterworth 4-pole phaseless digital filter was used. The difference in the displacement time histories for the 180-Hertz data and the unfiltered data is negligible. The acceleration predictions from the $\mathrm{CD}$ analysis were filtered in the same manner.

Accelerometer data from a single accelerometer from the single-car test had been filtered using a 30-Hertz low-pass filter [1]. After reviewing all of the accelerometers from the single and two-car tests and SAE J211.1, it was apparent that error in the integrated displacement data had been introduced by overfiltering the acceleration. The single-car test data was reprocessed in accordance with $\mathrm{J} 211.1$. The corrected results are presented in Appendix B. The peak acceleration is approximately $14 \mathrm{Gs}$ when a CFC 30 is used in filtering the accelerations, versus a peak of about 38 Gs that results from using a CFC 60 filter. As discussed in the next section, the peak acceleration is not particularly significant in terms of the collision environment experienced by an unrestrained occupant. 
An appropriate accelerometer had to be selected to represent each car. All of the eleven filtered longitudinal acceleration traces were reviewed (see Figure 6 and Figure 7 for accelerometer locations.) There is a time delay in the signal for locations that are further towards the rear of each car. Elastic response of the car body has the largest effect at the rear of each car. A simple average of all of the accelerometers masks the relevant detail from the signal.

Impacting Car End

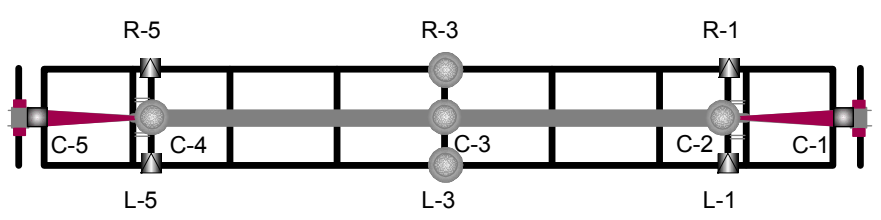

Three-axis Accelerometer Locations

V Single-axis (vertical) Accelerometer Locations

$\square$ Single-axis (longitudinal) Accelerometer Location

Underframe Plan View

Figure 6. Leading Car Accelerometer Locations

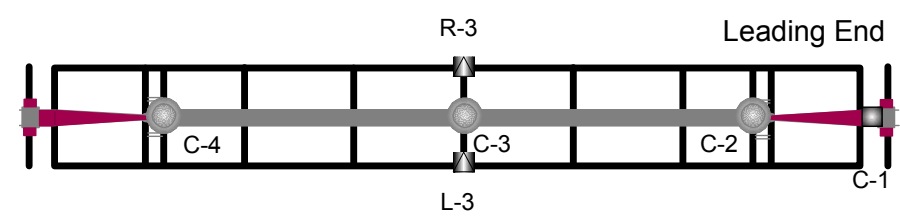

Three-axis Accelerometer Locations

\Single-axis (vertical) Accelerometer Locations

$\square$ Single-axis (longitudinal) Accelerometer Location

Underframe Plan View

\section{Figure 7. Trailing Car Accelerometer Locations}

The accelerometers labeled C-3 in both the leading and trailing cars were used to represent the longitudinal motion of the respective car bodies. These accelerometers were both located on the center sill at the longitudinal center of the car, near the center of gravity. Due to this mounting location, it is expected that the data would be less affected by car body pitch and yaw, than data from accelerometers located further away from the $C G$.

\section{TEST AND ANALYSIS RESULTS \\ Force/Crush Behavior}

During the two-car impact test, most of the damage occurred at the impacting end of the lead car, which crushed approximately 6 feet (see Figure 8 and Figure 9 for pre- and post-test photos of the impacting end of the lead car). There was little damage at the coupled connection between the cars. The peak force between the lead car and the impact wall was nearly 2.5 million pounds, with a steady force of approximately 500,000 pounds. Figure 10 shows the comparison of the force/crush behavior measured during the test and calculated with the $\mathrm{CD}$ analysis. The $\mathrm{CD}$ analysis matches the peak force, timing, steady value and total crush very well. The estimated peak force on the wall is a function of the acceleration of the two-car bodies, which is influenced by the CFC used to filter the acceleration.

Both the single-car and two-car collision dynamics models were modified subsequent to the two-car test to further improve the results of each model. The test and analysis data for both tests compare well, in terms of the timing of the peak force, the average force and the total crush.

For comparison, the force/crush behavior from the singlecar test is plotted with the two-car test data in Figure 11. The curves from both tests are very similar in terms of peak force and steady force. Total crush in the two-car test is about 10 inches greater, since the kinetic energy was slightly higher than in the single-car test.

As an additional check that the force and displacement data were calculated properly, the energy absorbed during the collision was calculated by integrating the force/crush curve and comparing the result to the total energy available, i.e., $1 / 2 * \mathrm{M}^{*} \mathrm{~V}^{2}$. While the respective test and analysis curves aren't identical, the total energy absorbed, i.e. the area under the each of the curves, varies by less than $1 \%$.

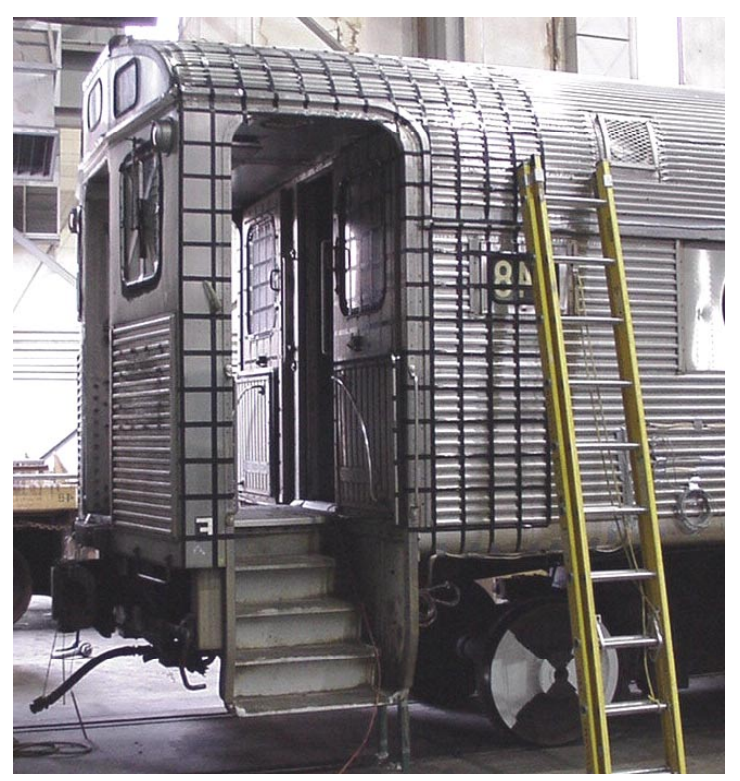

Figure 8. Photo of Impact End of Leading Car Prior to Two-Car Test 


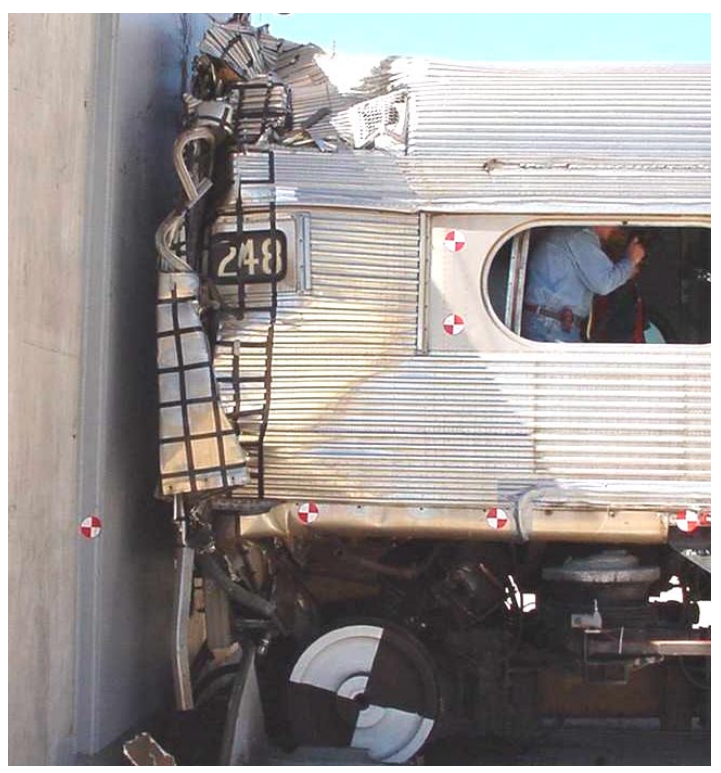

Figure 9. Photo of Impact End of Leading Car After Two-Car Test

The mode of crush of the draft sill was quite different between the two tests. In the single-car test, the draft sill split along the longitudinal seam welds of the box. The top plate folded up in the vertical plane, and the 2 side plates folded up in the lateral plane. The tapered section nearest the body bolster was intact. In the two-car test, the widest part of the draft sill at the end of the car stayed relatively intact, pushing back on the tapered section of the draft sill, which buckled extensively. Although the mode of crush of the draft sills was different in each test, the force/crush behavior of the car was similar in both tests.

\section{Two Car Test}

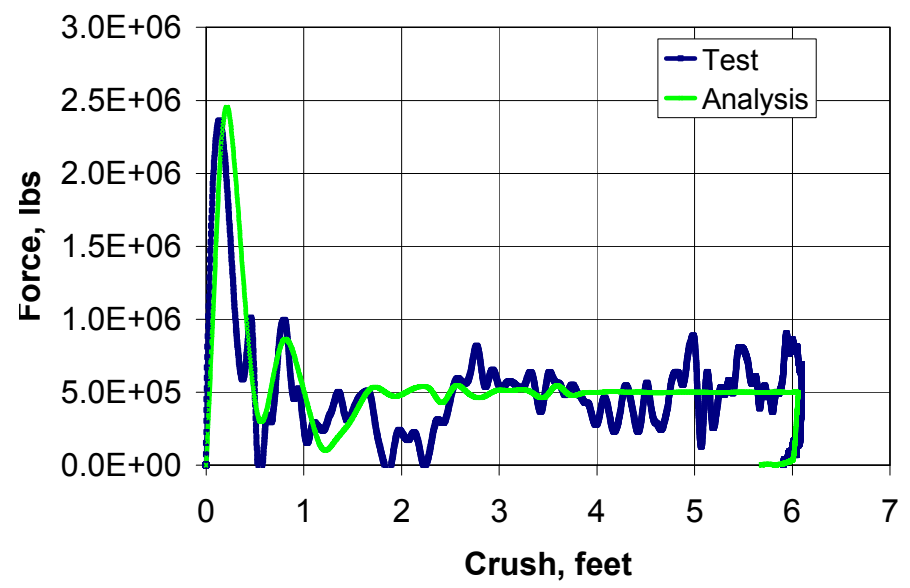

Figure 10. Comparison of Force/Crush Behavior from Two-Car Test

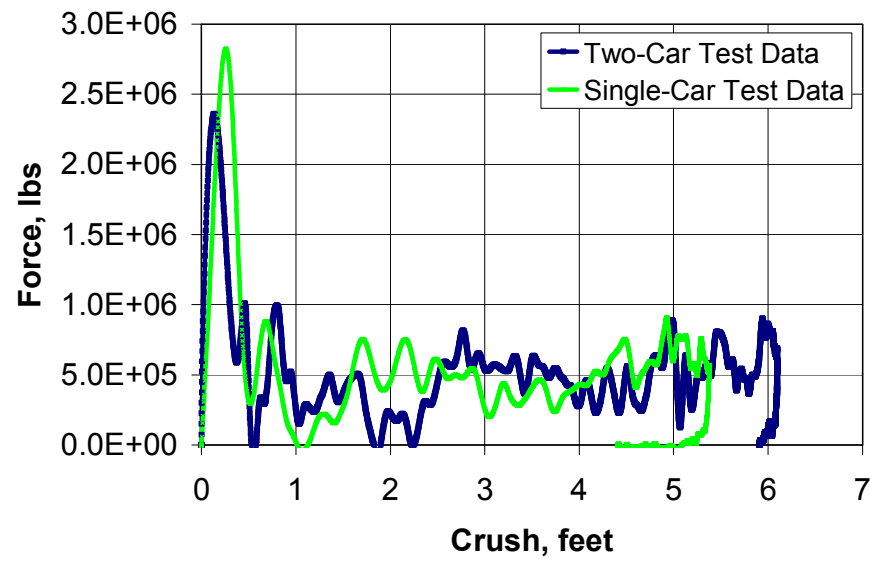

Figure 11. Comparison of Force/Crush Behavior from Single-Car and Two-Car Tests

\section{Gross Motion}

The two cars remained coupled during the test, but buckled in a saw-tooth mode as intended. The maximum lateral displacement between the cars during the collision was approximately 30 inches, with a final lateral displacement of 15-inches following the test (see Figure 12). The left track buckled under the lateral load from the front truck of the trailing car, allowing the right wheels of the front truck of the trailing car to drop.

The impacting end of the leading car rose about 6 inches during the impact, and came to rest with all wheels from both trucks still on the track.

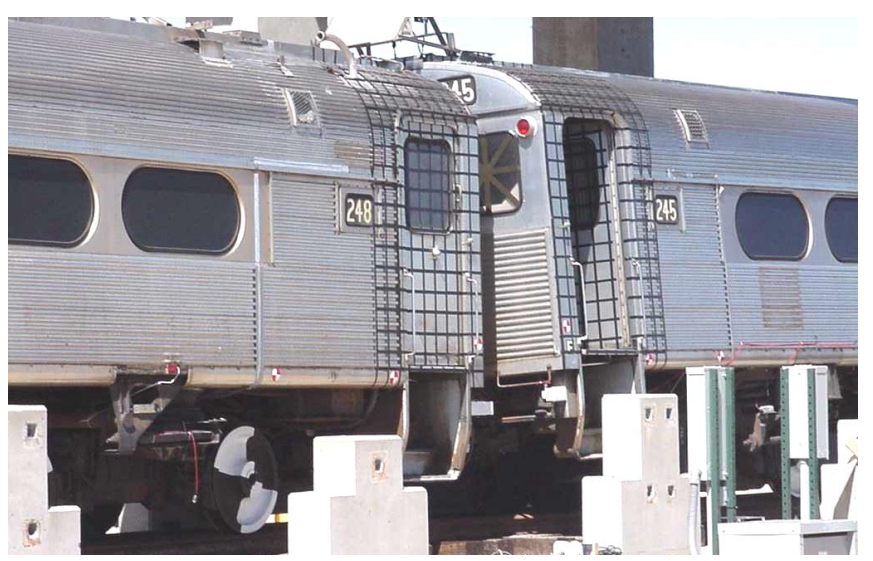

Figure 12. Photo of Coupled Connection After Two-Car Test

The deceleration time histories from the leading and trailing cars are shown in Figure 13 and Figure 14, respectively, along with the corresponding data from the $\mathrm{CD}$ analysis. Although the estimated force acting on the wall was similar in both tests, the accelerations of the cars were very different. The trailing car in the two-car test acts to minimize the acceleration of the lead car during the first 100 milliseconds. 
While the lead car is decelerating due to the impact with the wall, the trailing car is simultaneously trying to accelerate the lead car. The peak acceleration of the trailing car is much less than that of the leading car because it is effectively buffered by the crushing of the leading car.

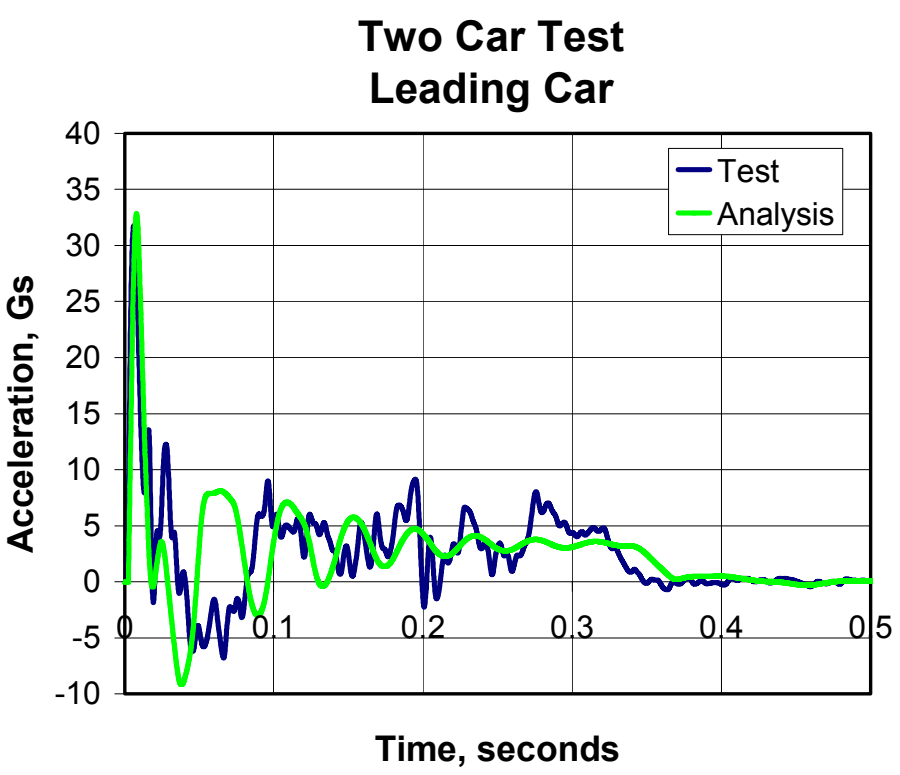

Figure 13. Comparison of Longitudinal Accelerations of CG of Leading Car from Two-Car Test

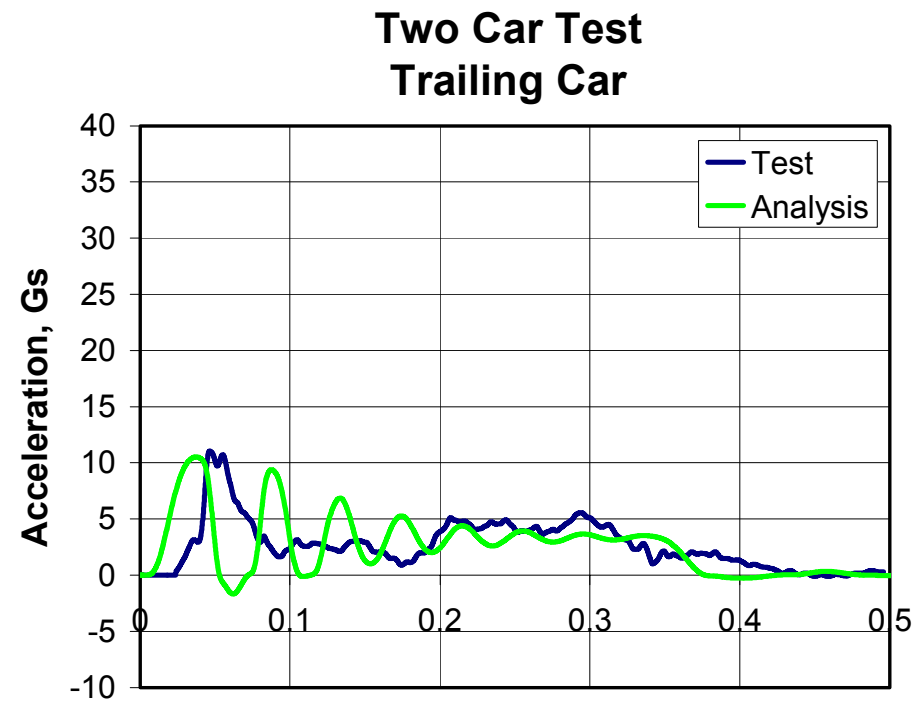

Time, seconds

Figure 14. Comparison of Longitudinal Accelerations of CG of Trailing Car from Two-Car Test

Qualitatively the model predicts the details of the decelerations very closely. The $\mathrm{CD}$ analysis predicts a high initial peak followed by a reversal of the acceleration for the lead car, just as measured in the test. The overall shape of the acceleration time history for the trailing car in the CD analysis compares favorably with the test measurement. The only significant difference in the test and $\mathrm{CD}$ analysis is in the timing of the peaks and the oscillation in Figure 13 and Figure 14. This difference is attributable to the representation of the coupler.

The lateral car body accelerations in the two-car test were small, with high frequency peaks on the order of 2-3 Gs. Vertically, the high frequency peaks were about 5 Gs during the first 0.3 seconds, with a good deal of elastic vibration. After the elastic vibration died out, the acceleration had a sinusoidal pattern at about 6 Hertz with an amplitude of 2-3 Gs, that damped out after about 3 cycles.

\section{Secondary Collision Environment}

The peak acceleration is not particularly significant in terms of the collision environment experienced by an unrestrained occupant. The occupant's velocity relative to the vehicle governs the severity of the secondary impact, which is a function of the car's acceleration time history. The secondary impact velocities for the forward-facing test dummies in the leading and trailing cars are plotted in Figure 15 and Figure 16, respectively. Both curves are based on the acceleration time history as measured in the test and calculated in the CD analysis.

The force imparted to the test dummy is related to the relative speed at impact. The heads of the unrestrained dummies seated in the forward-facing commuter seats would travel approximately 2 feet before striking the back of the seat ahead, or 2.5 feet if they were seated in the inter-city seats (In service, inter-city seats are generally positioned with a seat pitch about 6 inches greater than that of commuter seats, thus the 6 inch difference in travel distance). The relative impact velocities for unrestrained dummies in the commuter and intercity seats in both cars of the two-car test were approximately 13 $\mathrm{mph}$ and $16 \mathrm{mph}$, respectively. Corresponding data for the single-car test were $19 \mathrm{mph}$ and $22 \mathrm{mph}$ (see Appendix B).

The CD analysis provides a very good estimate of the secondary impact velocity. The overall shape of the curves are similar. The difference in the timing of the dips in Figure 15 and Figure 16 are a consequence of the modeling of the coupler.

Relative impact velocity is used as a simple measure to compare the severity of different collisions with different crash pulses. It is not meant to be used to predict the likelihood of injury or fatality for occupants exposed to a particular environment. For a more accurate identification of actual forces and accelerations likely to be experienced by occupants in a collision, it is necessary to review the data collected by the instrumented test dummies [4]. 


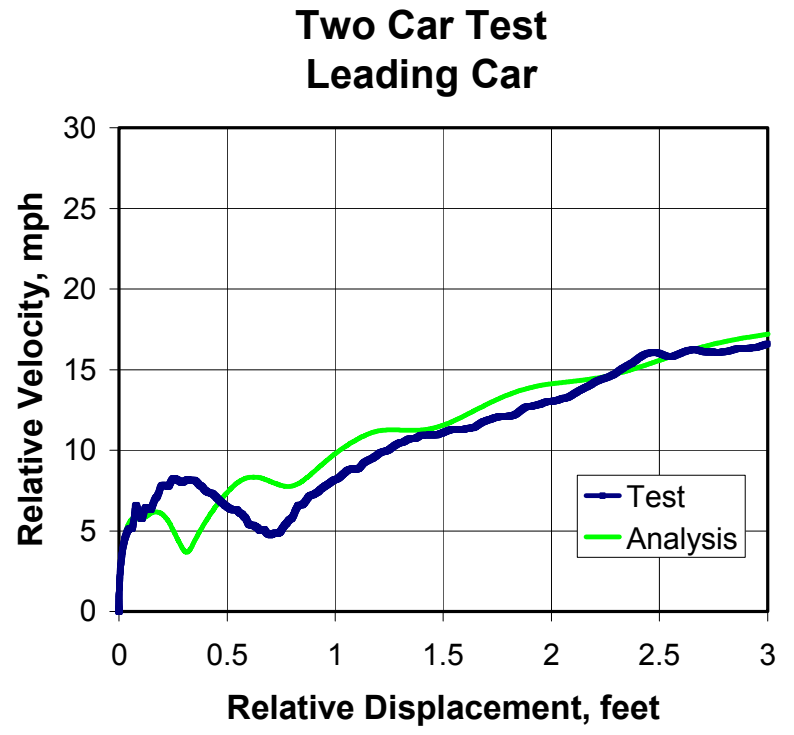

Figure 15. Comparison of Secondary Impact Velocity for Dummies in Leading Car of Two-Car Test

\section{Two Car Test Trailing Car}

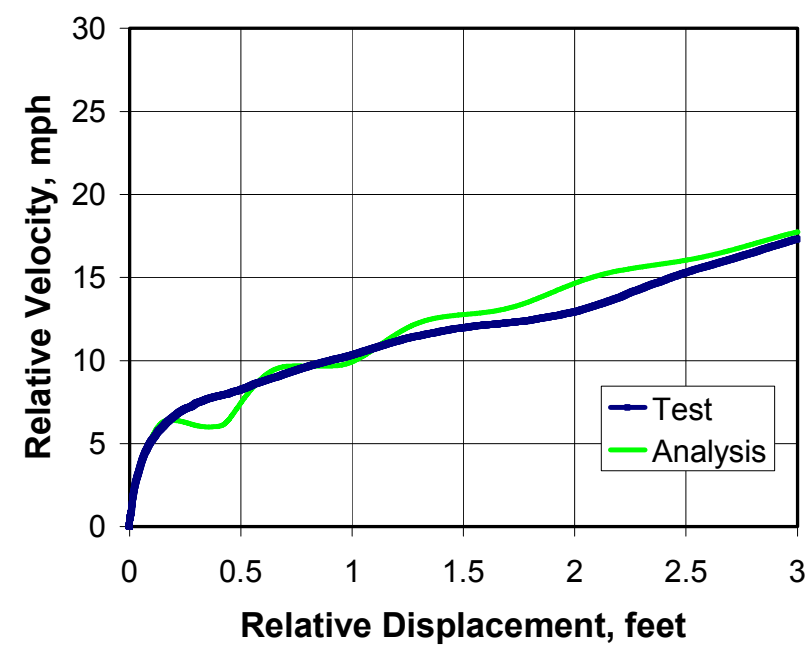

Figure 16. Comparison of Secondary Impact Velocity for Dummies in Trailing Car of Two-Car Test

\section{DISCUSSION AND CONCLUSIONS}

As laid out in the test-specific objectives, the gross motion of the car body was measured, as was the force/crush behavior at the impacting end of the car. The car-to-car interaction was observed along with the failure modes of the principal structural members. The effectiveness of the different occupant protection strategies is covered in reference [4].

The single-car and two-car collision dynamics models have been modified to better agree with the results from both tests.
The model results presented have been shown to estimate the gross motion and force/crush behavior from the respective tests reasonably well.

The results from the first two full-scale tests have been used to characterize the collision behavior of conventional commuter rail cars. The results indicate that the force/crush behavior is not influenced by the failure mode of the principle structural members. The collision dynamics model has been shown to estimate the force/crush behavior reasonably well for frontal collisions. The model can be extrapolated to look at frontal collisions involving more coupled cars and at varying collision speeds. The model can also be modified to evaluate the influence of different force/crush characteristics on the secondary impact velocity an occupant would experience in a collision.

The results from the two-car test have been used to demonstrate that the trailing car serves to reduce the severity of the acceleration time history of the leading car. The force applied to the leading car by the trailing car minimizes the duration of the initial acceleration peak of the leading car, which reduces the secondary impact velocity with which an occupant strikes the interior.

The collision dynamics model predicted the lateral buckling of the cars when there was a small perturbation in the direction of the impact force. However, the model could be improved to better capture the timing of the longitudinal forces transferred through the coupler. From the test data, it appears that the coupler compresses several inches before any significant force develops. Tuning this "gap" in the model will result in a better estimation of the timing of the acceleration peaks of both cars. Also, the model requires more damping at the coupler to minimize the longitudinal oscillation of both cars.

The vertical and lateral motion of the car bodies didn't appear to have a significant influence on the kinematics of the test dummies. However, more analysis of the test data is necessary to understand the influence of the car body bounce, pitch and yaw motion on the tendency for cars to buckle laterally or vertically.

Relative impact velocity can be used to compare the relative severity of different collisions with different crash pulses. Previous sled tests have been conducted using a triangular crash pulse, or acceleration time history, with a peak of 8 Gs and a duration of 0.25 seconds. This acceleration time history was developed from earlier single degree of freedom collision dynamics models, in lieu of actual test data. The $8 \mathrm{G}$ acceleration curve may appear much less benign than the acceleration curves measured in the single-car and two-car tests because the peak of $8 \mathrm{Gs}$ is much less than the $32-38 \mathrm{G}$ peak measured in the impacting car from the two tests. However, the corresponding secondary impact velocities for test dummies subjected to the $8 \mathrm{G}$ crash pulse would be $19 \mathrm{mph}$ and $20 \mathrm{mph}$ 
for unrestrained, forward-facing dummies seated in commuter seats and inter-city seats, respectively (see Appendix B.) The corresponding secondary impact velocities for the two-car test were significantly lower at $13 \mathrm{mph}$ and $15 \mathrm{mph}$, respectively. Therefore, the peak acceleration can not be taken alone as a measure of collision severity.

In future work, the coupler element will be refined to better estimate the timing in the development of the force at the coupler and to minimize the longitudinal oscillation of the cars. The two-car CD model will then be extended to model the train-to-train test scheduled for the fall of 2000 .

\section{ACKNOWLEDGMENTS}

The tests discussed in this paper were performed as part of the Equipment Safety Research Program sponsored by the Office of Research and Development of the Federal Railroad Administration. The authors would like to thank Dr. Tom Tsai, Program Manager, and Ms. Claire Orth, Division Chief, Equipment and Operating Practices Research Division, Office of Research and Development, Federal Railroad Administration, for their support. The authors would also like to thank Mr. Gunars Spons, Federal Railroad Administration Resident Engineer at the Transportation Technology Center, for managing the full-scale test effort, and John Zolock, Volpe Center, for processing the test data.

\section{REFERENCES}

[1] Tyrell, D., Severson, K., Perlman, A.B., "Single Passenger Rail Car Impact Test Volume I: Overview and Selected Results," US Department of Transportation, DOT/FRA/ORD00/02.1, March 2000.

[2] VanIngen-Dunn, C., "Single Passenger Rail Car Impact Test Volume II: Summary of Occupant Protection Program," U.S. Department of Transportation, DOT/FRA/ORD-00/02.2, March 2000.

[3] Tyrell, D., Brickle, B., Severson, K., Perlman, A.B., VanIngen-Dunn, C., "Rail Passenger Equipment Crashworthiness Testing: Requirements and Implementation," to be presented at the 2000 ASME Winter Annual Meeting.

[4] Tyrell, D., Zolock, J., VanIngen-Dunn, "Rail Passenger Collision Tests: Analysis of Occupant Protection Measurements," to be presented at the 2000 ASME Winter Annual Meeting.

[5] Mayville, R.A., Hammond, R.P., Johnson, K.N., "Static and Dynamic Crush Testing and Analysis of a Rail Vehicle Corner Structural Element," Proceedings of the 8th ASME Symposium on Crashworthiness, Occupant Protection and Biomechanics in Transportation November 14-19, 1999, Nashville, Tennessee.

[6] Wierzbicki, T., "Body Shell and Beam Interaction," Draft Final Report, U.S. Department of Transportation, Cambridge, MA, 1999.
[7] Tyrell, D., and K.J. Severson, "Crashworthiness Testing of Amtrak's Traditional Coach Seat," DOT/FRA/ORD-96/08, October 1996.

[8] VanIngen-Dunn, C., Manning, J., “Commuter Rail Seat Testing and Analysis," Draft Final Report, U.S. Department of Transportation, Cambridge, MA, 2000.

[9] White, J.H., Jr., "The American Railroad Passenger Car," The Johns Hopkins University Press, 1978.

[10] Kirkpatrick, S.W., and Simons, J.W., "High-Speed Rail Collision Safety," Rail Vehicle Crashworthiness Symposium, DOT/FRA/ORD-97/08, 1998.

[11] Mayville, R., Rancatore, R., Tegeler, L., "Investigation and Simulation of Lateral Buckling in Trains," Published in Proceedings of the 1999 IEEE/ASME Joint Railroad Conference, April 13-15, 1999, IEEE Catalog Number 99CH36340, ASME RTD Volume 16.

[12] ADAMS, Version 9.0.1, Mechanical Dynamics, Inc., Ann Arbor, Michigan.

\section{APPENDIX A - PARAMETERS USED IN TWO-CAR COLLISION DYNAMICS MODEL}

The CD model was developed using the Adams computer program [12]. Contact between the rigid impact wall and the front plate of the colliding vehicle is governed by an impact element. This impact element generates an elastic restoring force based on Hertz contact when the colliding objects try to penetrate one another. The impact stiffness and damping values are $6.0 \mathrm{E}+07 \mathrm{lb} / \mathrm{ft}$ and $2.0 \mathrm{E}+04 \mathrm{lb}-\mathrm{s} / \mathrm{ft}$, respectively.

The front end plate is connected to the main car body by five springs. The springs account for the dominant structural elements: draft sill, side sills and roof sills. The majority of the longitudinal load is born by the draft sill. The corresponding force/crush curves are plotted in Figure A1.

\section{Spring Characteristics}

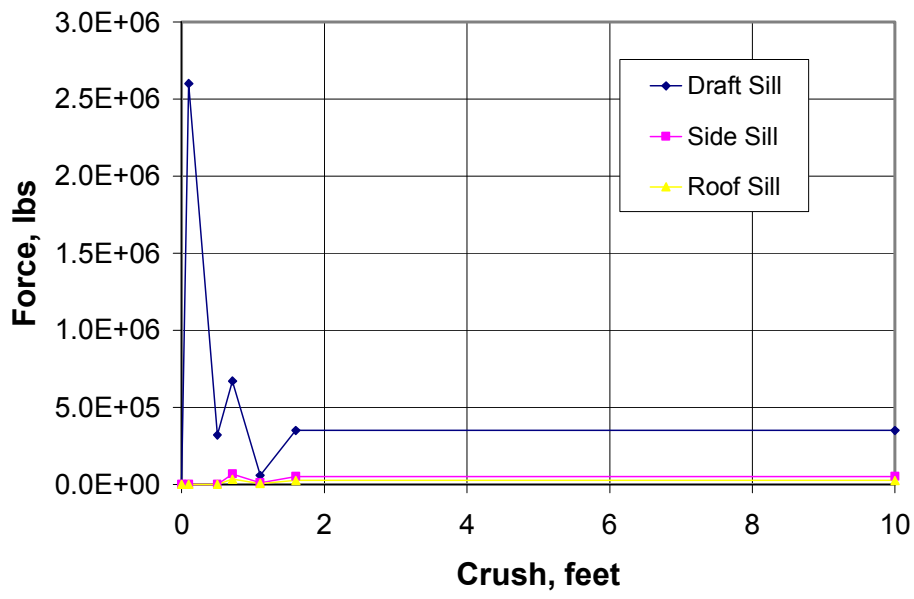

Figure A1. Longitudinal Force/Crush Behavior of Collision Springs 
The secondary suspension between the trucks and car bodies is a combination of spring and damper elements that are linear for small displacements and represent compression and extension stops for large displacements. These elements transmit forces between the car bodies and trucks in the lateral, longitudinal and vertical directions. Each truck has elements to transmit vertical and lateral forces to the rails, one for each rail.

Both kinematic and flexibility characteristics are accounted for in the coupler connection between the two vehicles.

Table A1 lists the centroidal mass and principal mass moments of inertia that were prescribed to represent the bodies of the leading passenger car in the two-car model. These values were adapted from a similar Adams trainset model [11].

Table A1. Vehicle Parameters

\begin{tabular}{|c|c|c|c|}
\hline Property & Main Body & Trucks & Front Plate \\
\hline Mass (lb-m) & 35,579 & 13,700 & 2,252 \\
\hline $\begin{array}{l}\text { Centroidal Roll } \\
\left(1 \mathrm{bm}-\mathrm{ft}^{2}\right)\end{array}$ & $9.67 \mathrm{E}+05$ & $3.55 \mathrm{E}+04$ & $9.617 \mathrm{E}+04$ \\
\hline $\begin{array}{l}\text { Centroidal pitch } \\
\left(1 \mathrm{bm}-\mathrm{ft}^{2}\right)\end{array}$ & $2.22 \mathrm{E}+07$ & $1.08 \mathrm{E}+05$ & $4.746 \mathrm{E}+07$ \\
\hline $\begin{array}{l}\text { Centroidal yaw } \\
\left(1 \mathrm{bm}-\mathrm{ft}^{2}\right)\end{array}$ & $2.24 \mathrm{E}+07$ & $9.28 \mathrm{E}+04$ & $4.894 \mathrm{E}+04$ \\
\hline
\end{tabular}

\section{APPENDIX B - SELECTED SINGLE-CAR TEST} RESULTS

Both the test and analysis data [1] from the single-car test were reprocessed in accordance with J211.1. Accelerometer C-3 at the center of the car was used here, rather than $\mathrm{C}-2$, which was used for data presented in [1]. Figure B1 presents the force/crush behavior from the test results, $\mathrm{CD}$ analysis and $\mathrm{FE}$ analysis. A comparison of the results in Figure B1 with Figure 11 in [1] shows higher peak values for the reprocessed data, but there is little change in the steady force values.

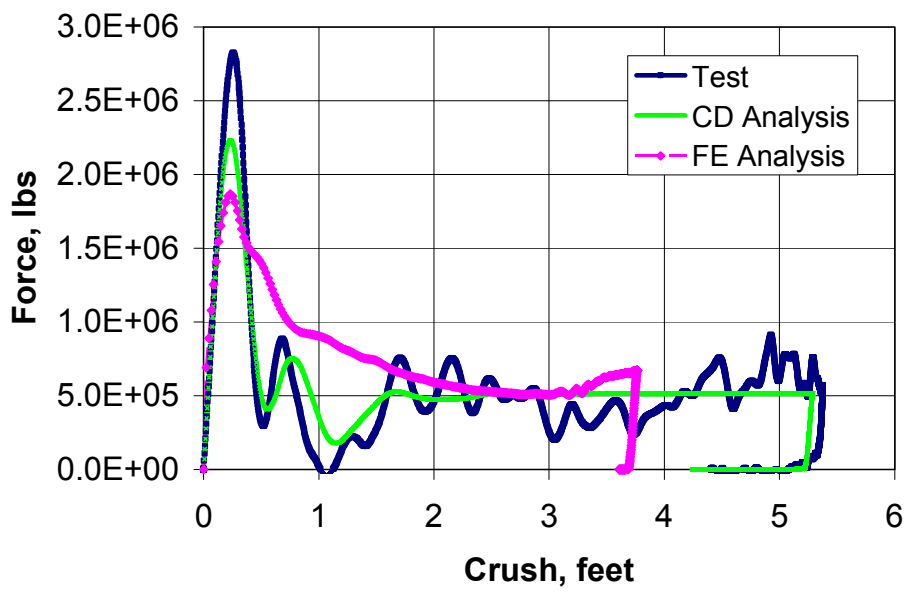

Figure B2 shows the reprocessed acceleration data. A comparison of the results in Figure B1 with Figure 11 in [1] shows higher peak values for the reprocessed data, but there is little change in the steady acceleration values.

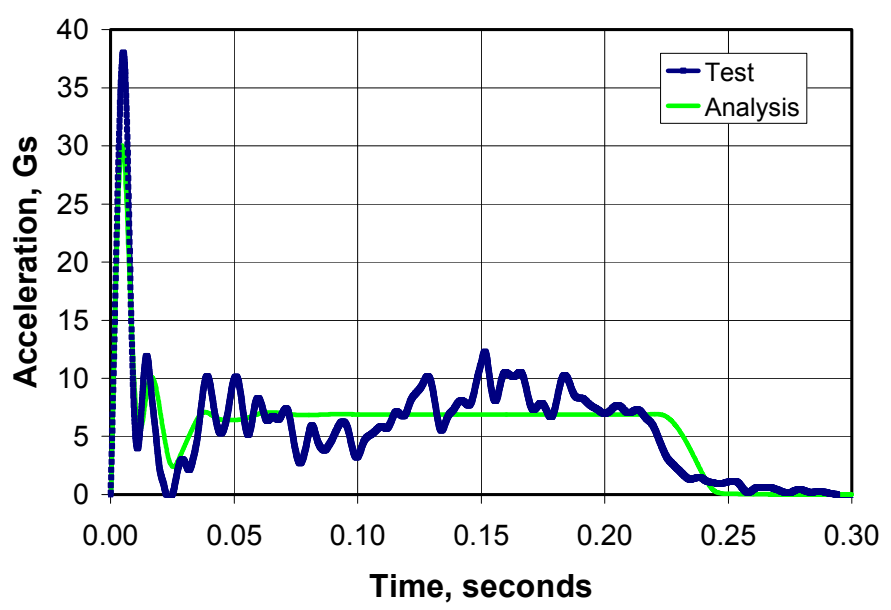

Figure B2. Comparison of Longitudinal Accelerations of Car Body CG

Reprocessed data in Figure B3 can be compared with the results in Figure 15 of [1]. In this case the reprocessing of the data does not affect the results, as expected.

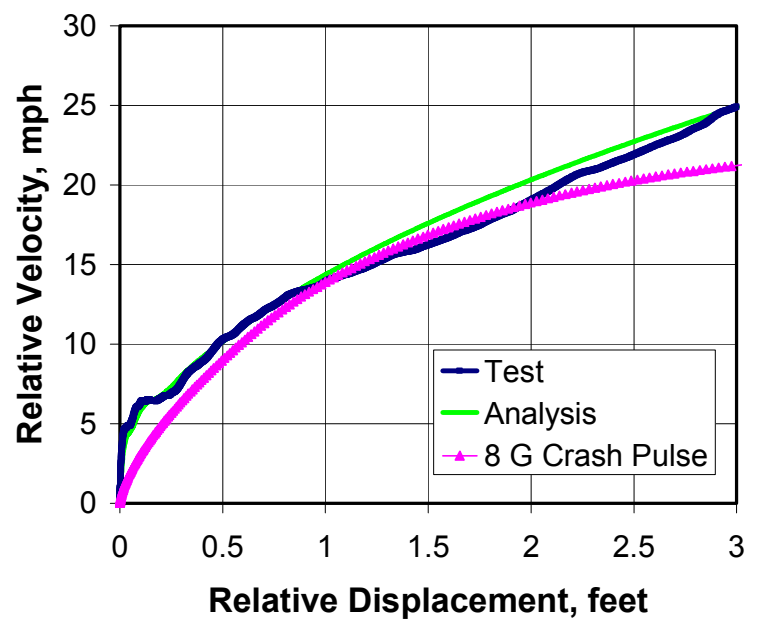

Figure B3. Comparison of Secondary Impact Velocity for Dummies in Single-Car Test and an 8G Sled Test

Figure B1. Comparison of Force/Crush Behavior 